\title{
El tiempo y la escritura como narratividad y representación
}

\section{Time and writing as narrative and representation}

\author{
Rocío Polanía Farfán \\ Profesora Asistente \\ Universidad Surcolombiana
}

\section{Procmio}

Ricœur afirma que el problema de la representación del pasado por los historiadores puede enunciarse en términos de un pacto tácito que se establece entre el lector del texto histórico y el autor. El primero espera que se le proponga un "relato verdadero" y no una ficción. El segundo, tiene entre manos el problema de saber si la escritura de la historia puede respetar ese pacto, cómo puede hacerlo y hasta qué punto (Ricœur, 2000: 3). Desde esta perspectiva, podemos decir que la tarea del historiador no se concreta sólo al observar los hechos. Él, además, de plantearse una serie de interrogantes frente a los acontecimientos, debe articular todo una metodología que le permita estudiar fenómenos sociales en relación con el comportamiento cultural, así como también debe esclarecer que el método de la investigación histórica es, sin duda, una parte de la investigación de la sociedad, de la investigación social o, si se quiere, de la investigación histórico-cultural.

La historia, como una disciplina positiva o científica rígida orientada a presentar acontecimientos reales ordenados cronológicamente, no toma partido ni se involucra con una posición crítica frente al presente; la historia no puede seguir siendo una forma de trasmisión de información, la historia debe situarse dentro del discurso narrativo que permita dar cuenta de lo se considera significativo del pasado al presentarlo en forma de relato o discurso. White (2003: 145) sostiene que "el problema principal para cualquier teoría del escrito histórico no reside [...] en la posibilidad o imposibilidad de una aproximación científica al estudio del pasado, sino, más bien, en explicar la persistencia de la narrativa en la historiografía". En este sentido, en el ámbito de los estudios históricos, la narrativa no ha solido ser considerada ni como un producto de una teoría ni como la base de un método, sino más bien como una forma de discurso que puede o no utilizarse para la representación de los acontecimientos históricos, en función de si el objetivo primario es describir una situación, analizar un proceso histórico o bien contar una historia.
Tal vez al iniciar un trabajo sobre investigación histórica de inmediato asaltan diferentes dudas y cuestionamientos que involucran la reflexión y el análisis de lo histórico: ¿cómo escribir una historia explorativa y diferente de aquellas historias informativas que solían escribir los historiadores tradicionales? ¿Qué tipos de preguntas se deben realizar frente a los fenómenos de la realidad que de alguna manera se quieren comprender? ¿Cuáles son los métodos que permiten observar mejor los hechos investigados? \&A qué se está haciendo referencia cuando se habla de una historia objetiva? ¿Qué es lo viejo y lo nuevo en la escritura de la historia? ¿Toda historia social es, ya desde el principio de su existencia, una historia nueva?

Frente a estos interrogantes, se puede afirmar que existe hoy una diversidad de formas de hacer historia en lo que corresponde a aspectos tales como la manipulación concreta de la dimensión temporal donde se sitúan los fenómenos estudiados; el manejo específico de las categorías de verdad y objetividad; la utilización de diversas escalas de observación de los hechos investigados; el problema de la relación teórico-metodológica entre acción individual y estructuras sociales; y las técnicas de escritura o exposición, con el relato en el centro de la discusión.

Dos aspectos se hacen presentes súbitamente, si se reflexiona sobre esa entidad que envuelve a todo ser volviéndole finito, entre tanto que ella se revela ante la intuición y ante la más vecina realidad como un monstruo eterno que devora todas las cosas y los seres en su huida. Pero también les garantiza el movimiento: un movimiento que les permite en cierta medida a esas cosas y sucesos (en especial a los seres), autoconocerse o darse a conocer y en últimas a relatarse, con el propósito de postergarse, de prevalecer en la memoria colectiva de la especie; una especie capaz de recoger sobre sí todos los datos y sucesos del mundo, los mundos posibles y el mundo de la vida misma.

Tales aspectos son las categorías de verdad y objetividad; y la escritura, el relato o el mito desenvolviéndose en el tiempo de la especie humana para constituir el constructo de la historia o "su" 
historia, quizás proviene de un representante de la especie humana o de un fragmento de ella. Esto quiere decir que el relato como narratividad siempre va a depender del enfoque, metodología o visión del mundo con que el representante de la historia indaga sobre la temporalidad de los acontecimientos.

Por estas razones podemos decir que la tarea del historiador o representante no se limita sólo a la observación los hechos; él, además de plantearse una serie de interrogantes frente a los acontecimientos, debe articular todo una metodología que le permita estudiar fenómenos sociales en relación con el comportamiento cultural. Asimismo, debe esclarecer que el método de la investigación histórica es, sin duda, "una parte de la investigación de la sociedad, de la investigación social o si se quiere de la investigación histórico cultural" (Arostegui: 71). Pero una investigación histórica cultural no puede prescindir del mundo simbólico, de los rastros míticos ni del animal simbólico que imprime las representaciones de su mundo.

Es factible observar cómo dentro del mundo simbólico se entrelazan el tiempo y la escritura como relato o bien como narración en el ámbito histórico. En el mundo simbólico griego, Cronos es la personificación del tiempo. Hijo a su vez de Urano, representación del cielo. Aquí se vislumbra ya la idea de la astronomía y de los calendarios astronómicos como medidores del tiempo. En este relato simbólico, Cronos destrona a su padre, es decir, que el tiempo deja atrás el cielo para instaurarse en la escritura-grabado-registro como primer vestigio histórico. La subsecuente venganza urdida por su madrea Gea (el punto de referencia: la tierra punto de partida e historia humanas), consiste en cortar los órganos genitales de Urano con una hoz: representando el acto de segar la muerte que no perdona aun a las estrellas y que corta el hilo de la historia en términos humanos. Cronos arroja los genitales de su padre a sus propias espaldas simbolizando que las generaciones y la descendencia son dejadas atrás por el tiempo.

Así, tenemos los conceptos de eternidad del tiempo y el de la muerte como cesación de un suceso en la eternidad: del que deviene el olvido. Simbólicamente dicha eternidad versus olvido, se resuelve con el truco de Rea frente a Cronos que devora a sus hijos para no ser destronado. Rea da una piedra a Cronos en lugar de su hijo Zeus: La piedra sobreviviendo a grandes lapsus de tiempo. Cuando Zeus es mayor (por decir también cuando la civilización es más avanzada) hace un filtro que le obliga a devolver todos los hijos que había devorado y se inicia una guerra: he ahí el nacimiento de la historia, que hace devolver del olvido aquello que había sido devorado por el tiempo, una guerra para sobrevivir en la memoria colectiva de la humanidad hasta el último descendiente. Batalla que aún no cesa: el ímpetu humano por tratar de desentrañar el pasado, dirigir el presente y construir el futuro.

Se puede visionar a la abstracción hombre en constante guerra con el tiempo, que él traduce en el mundo de la civilización moderna en el develamiento histórico; es decir, que el hombre sin historia dejaría de ser hombre. Por ello Jaspers (1981: 240) comenta que "el hombre necesita de la historia para asumir aquello que fue posible para el hombre referido a los grandes ejemplos".

Gran parte de esa necesidad se ve satisfecha en la escritura como relato, narración, crónica o anal desde su aparición, al igual que de sus antecesores de tradición oral. En palabras de Hegel, citado por White (1992: 27), "...la narración histórica aparece simultáneamente con los hechos y acontecimientos propiamente históricos. ...el curso uniforme de los acontecimientos que presupone dicha condición no es objeto del recuerdo; pero los hechos más señalados o los giros del destino pueden incitar a Mnemosyne a conservar esas imágenes...". Hegel cita a la diosa de la memoria, hija de Urano. Zeus se une con la titanida de cuya unión nacen las nueve musas. Dicho nacimiento tiene la trascendencia o giro que incita al registro histórico, más un registro que aparezca como narración histórica. La verificación más o menos de la realidad estribaría no en una historia verdadera, sino en conseguir dar a la realidad una forma de relato. Como diría Benedetto Croce: "donde no hay narrativa no hay historia" (White, 1992: 21).

La historia como disciplina de conocimiento fue precisada dentro de un rígido marco intelectual positivista, que se concreta en la formulación de un conocimiento humano racional objetivo, neutro, plano, que no toma partido, no critica el presente, no se involucra en los debates actuales. Esta forma de pensamiento histórico fue estimulada bajo las concepciones fundamentales de las estructuras de pensamiento y los sistemas de creencias a través de los cuales se ha desarrollado la cultura occidental y se basaba en una comprensión de la existencia humana en la repetición cíclica de una identidad originaria ideal. En ese momento la historia fue posible porque se comenzaba a concebir un modo particular de articulación de la concepción de la existencia humana insertada en el tiempo, como un proceso de perfeccionamiento indefinido según una finalidad racionalmente determinada.

La concepción de la existencia humana insertada en el tiempo cobra validez en la escritura, huella o narración de dicha existencia desde el imaginario humano. Es el atisbo del puente entre el pensamiento mágicosimbólico y el pensamiento racional en la medida del tiempo como ciencia exacta. No obstante, la historia como una disciplina positiva o científica rígida que no toma partido ni se involucra con una posición crítica frente al presente, descontentándose de los rasgos simbólicos de cualquier narración, se halla en la línea de fuego de lo que escribe Jaspers (1981: 240): "no es contra el método científico como tal, ni contra el recuerdo histórico, sino contra el supuesto historiador puramente científico contra quien se dirige el enojo de Nietzsche: porque presumen un saber que no tienen en 
modo alguno".

Lo referente a la posición crítica frente al presente no se cierne en la idea de Croce de que toda historia es historia contemporánea, sino más bien en que los acontecimientos históricos pueden ser repensados constantemente. Frente a esta postura dice Paul Veyne (1995: 423): "la historia es ora la sucesión de acontecimientos, ora el relato, de esa sucesión de acontecimientos". Siguiendo a Le Goff, un significado subyacente de historia es precisamente el de relato. Una historia puede ser un relato que puede ser verdadero o falso, con una base de "realidad histórica" o meramente imaginario y este puede ser un relato "histórico" o bien una fábula (Le Goff, 1997: 21-22). (No sobra agregar que tanto el étimon de fábula como el de Mithos tienen la acepción de narrar, de contar en forma hablada).

Regresando a la perspectiva temporal (circular y eterno), la acción humana estaba determinada por los códigos fijados en las formas de discurso. La radical ruptura con este concepto premoderno del tiempo determina el verdadero impulso que cobra la historia como principio nuclear de significación de la existencia humana. No se trata, por consiguiente, de la aparición de un modo concreto de concepción de la historia, sino de la incursión histórica de la propia historia por medio de la idea de progreso como solución al problema de la aprehensión social de la singularidad e irreversibilidad de los hechos tal y como se perciben por medio de los sentidos.

Por otro lado, los esquemas descriptivo-legitimadores de los nuevos órdenes sociales emergentes en las revoluciones económicas y políticas del XIX estaban basados en un esquema heroico del progreso humano estimulado por los avances de la ciencia y en un concepto épico de la relación del estado-nación. Estos trabajos son el resultado de una labor directa sobre los documentos, alentado por el amalgamiento lógicotextual (historia-relato positivista) de los acontecimientos protagonizados por ciertos sujetos que con su actividad heroica pueden ser perfectamente individualizados. Para el desarrollo de este tipo de trabajos las fuentes documentales poseen un carácter relevante y la acción humana es traducida en la expresión de un tiempo sin camino de retorno, en donde la causalidad queda circunscrita en la orientación temporal, racionalmente autorregulada, hacia un futuro previsible y deseable.

En este sentido, toda comunidad insertada en la historia no se reconoce ya en lo que es, sino en la idea de lo que quiere y debe ser. Dentro del esquema descrip tivo documental alentado por el amalgamiento lógico textual, "No es que cualquier texto dado pueda por sí solo invocar todo el mundo en que surgió o que un conjunto dado de textos puedan revelar por completo su mundo. Pero, en principio, parece afirmarse que hoy disponemos de los instrumentos para analizar los textos de una forma sólo tenuemente percibida o, si acaso, no utilizada plenamente por anteriores historiadores intelectuales y de otros géneros. Y estos instrumentos, se sugiere, son por lo general de naturaleza lingu?ística" (White, 1992: 197). En otra instancia, y desde una orientación temporal hacia un futuro predecible y deseable, "surge una división entre el historiador que desea principalmente reconstruir o explicar el pasado y el que está interesado o por interpretar o por usar su detritus como ocasión de sus propias especulaciones sobre el presente y el futuro" (White, 1992: 197-198).

Bajo esta dinámica de construcción historiografía, se puede determinar una carencia en los historiadores en cuanto al aspecto metodológico y más concretamente en la propuesta teórica: "los historiadores se han preocupado muy pocas veces de explicar, no sólo frente a los demás, sino también para sí mismos, la teoría a partir de la cual recomponían los datos básicos recogidos" (Lledó, 1978: 7). El historiador toma como referente para estudiar o plantear nuevas teorías, la historia que se encuentra plasmada en la realidad, los acontecimientos que caracterizan a la sociedad o sociedades concretas. El historiador escribe y describe la historia, en efecto, pero debe también "teorizar" sobre ella, es decir, reflexionar, argumentar y hallar fundamentos generales acerca de la naturaleza de lo histórico, así como sobre el alcance explicativo de su propio trabajo. Sin teoría no hay avance del conocimiento.

"Cuando el historiador analiza y critica la obra de sus colegas o predecesores para identificar los elementos ideológicos de la misma, tiene tendencia a presentar los puntos a debate en términos de contenido: temas, conceptos, argumentos, valores, etc. (...) el investigador considera haber interpretado adecuadamente por sí mismo y establecido como el tribunal supremo de autoridad y rectitud de sus propias interpretaciones" (White, 1992: 202). En este sentido es donde se traduce la expresión de un tiempo sin camino de retorno, pues la temporalidad es un obstáculo por el cual la historia no puede plasmarse en la realidad con facilidad. Por eso el historiador teoriza la historia a través de argumentos y reflexiones, que es más viable y posible a través de una narratividad en que se escribe y se describe la historia.

En términos generales, "una historia en manos de los historiadores puede ser entendida como una narración de acontecimientos colocados según su secuencia temporal" (Hernández, 1995: 219). De acuerdo con Topolski, "las imágenes históricas pueden revestir la forma de una serie de enunciaciones de todo tipo, incluyendo la de los modelos, y por ende, de proposiciones teórica. Las imágenes históricas se definen en cuanto a su contenido, por los factores de tiempo, espacio, así como por su objeto, la visión del mundo propia del historiador (...) y la teoría del proceso histórico" (Hernández, 1995: 219). De nuevo se desprende que sin teoría no hay avance del conocimiento, pero así mismo, lo que le da realce al relato teórico de la historia es su narratividad. 
"La crónica a menudo desea querer contar un historia", aspira a la narratividad, pero característicamente no lo consigue puesto que más que concluir una historia, simplemente la termina, deja las cosas sin resolver de forma similar a la historia. Si bien los anales representan la realidad histórica como si los acontecimientos reales no mostraran la forma de relato, el autor de la crónica la representa como si los acontecimientos reales se mostrasen a la conciencia humana en la forma de relatos inacabados. En definitiva, una historia bien narrada debe estar bien concatenada, deben sobresalir los nexos entre un acontecimiento $y$ otro hasta la extinción de ese fragmento de historia o de esa narración

No obstante, de alguna manera ese marco intelectual positivista sentó las bases para el desarrollo de una ciencia historiográfica que conquistó una intensa renovación, especialmente a partir del primer tercio del siglo XX. Más allá de encuentros y diferencias entre la historia de las estructuras representada por la escuela francesa de Annales y el marxismo como teoría general del movimiento histórico, estas tendencias incluyen como novedad un nuevo modo de comprensión de la temporalidad. La noción de estructura es el punto de partida, la cual pretende ser un principio de causalidad interna entre los fenómenos históricos de mayor alcance que la visión superficial historia-relato positivista. Para Braudel (1986: 70), estructura es "una organización, una coherencia, unas relaciones suficientemente fijas entre realidades y usos sociales...que el tiempo tarda enormemente en desgastar y en transportar...".

Este concepto braudeliano hace referencia a las diversas conexiones que se pueden establecer entre todas las dimensiones de la realidad histórica, ligadas directamente a una idea específica del tiempo histórico que se sedimentan en la aprehensión de las permanencias y de las resistencias al cambio en el plano de la larga duración. Lo que Braudel estableció entre las distintas longitudes de onda temporal histórica fue un modelo de tiempo estructurado por diferentes ritmos de aceleración, el tiempo como velocidad histórica, como velocidad diferencial de cambio; haciendo alusión a un tiempo corto, a un tiempo medio y a un tiempo largo, el de esas estructuras en las que se mantienen casi inalterables las condiciones sociales impuestas en una época determinada (Braudel, 1996, capitulo 3). W. Kula (1974) través de su modelo teórico explicado en su texto Teoría económica del sistema feudal, precisamente se refiere a una estructura temporal muy similar a la establecida por Braudel, cuando se refiere a las dinámicas de corto y largo plazo en la producción económica.

Vale la pena comparar las temporalidades de Kula (1974) con las de Fernand Braudel quien construyó un modelo de explicación cuya originalidad estriba en la descomposición del tiempo, considerado generalmente como algo lineal, plano y unitario en múltiples tiempos, claramente diferenciados entre sí y explícitamente vinculados a las distintas realidades históricas

Braudel introduce sus aportes de la larga duración, la mediana duración y la corta duración, descansando los dos últimos "en los fenómenos de duración larga", repercutiendo unos en los otros de manera simultánea, hasta destacar "lo que es fundamental y lo que es más o menos accesorio". Esta segregación del tiempo inicialmente fue un artificio pero luego la fundamentó a partir de los aportes del estructuralismo bebido en dos fuentes: en las tesis de Lévi-Strauss y en la lingüística de Saussure.

Para Lévi-Strauss, "esta alternancia de ritmo entre dos métodos -el deductivo y el empírico- ...dan a la antropología social su rasgo distintivo...es sin duda la única que hace de la subjetividad más íntima un medio de demostración objetiva... esta constante oscilación entre la teoría y la observación exige que ambos planos sean distinguidos siempre. Para volver a la historia, me parece que en ella ocurre lo mismo, según se trate de consagrarse a la estática o a la dinámica, al orden de la estructura o al orden del acontecimiento... además de un tiempo corto, existe un tiempo largo; que ciertos hechos pertenecen a un tiempo estadístico e irreversible, y otros a un tiempo mecánico y reversible" (Lévi-Strauss, 1970: XXXII-XXXIII).

Para Saussure "el orden sincrónico y el orden diacrónico... existe una oposición absoluta entre dos categorías de hechos: por un lado, la gramática, lo sincrónico, lo consciente; por otro, la fonética, lo diacrónico, lo inconsciente. Tan solo el sistema consciente es coherente; el infrasistema inconsciente es dinámico y desequilibrado; comprende a la vez legados del pasado y tendencias del futuro aún no realizadas" (Levi-Strauss, 1970: XXXIII-XXXIV). Es observable que en estas tesis sobresale el concepto de orden, tanto para las temporalidades reversible e irreversible como para las temporalidades sincrónica y diacrónica sujetas la una al orden del acontecimiento y la estructura y la otra en el orden del relato en los aspectos gramáticos y fonéticos, no obstante, asumidos como sostiene Saussure, como legados del pasado y tendencias del futuro aún no realizadas.

Braudel explicita los fenómenos en función de los distintos tiempos, los de larga duración son los más importantes para el historiador: corresponden a un siglo o a una época. La larga duración es el factor esencial determinante que incide en la duración media y en la duración corta que están representados en los acontecimientos y fenómenos de coyuntura. En la larga duración la frontera entre el pasado y presente no es fija.

Por lo anterior se puede concluir que con los aportes de Kula y de Braudel queda definitivamente superado el concepto de tiempo fijo, único, lineal, progresivo e inamovible que preconizaba la historia tradicional; de la misma manera esta nueva conceptualización sobre la temporalidad se constituye en una vía posible de 
realizar los análisis e interpretaciones históricas a partir de las orientaciones marxistas a partir del concepto del "modo de producción", constituido por una estructura global formada por tres niveles o instancias: el nivel económico, el nivel jurídico político y el nivel ideológico que articulan lo que se denomina "el análisis de estructura" y permiten aproximarnos a la totalidad social; se debe considerar que los distintos niveles no funcionan de forma aislada sino interrelacionados de manera orgánica y dialéctica. Por último, se puede considerar que las posturas de Kula y de Braudel no son contradictorias sino que pueden complementarse soportadas por un orden teórico que dé coherencia a las interpretaciones históricas.

La sustitución del acontecimiento por la estructura y de la corta por la larga duración conceptualizadas por Braudel y aplicada en el desarrollo del Mediterráneo, se convierte en paradigmas metodológicos para la época de gran relevancia. Estos fenómenos conceptuales se convierten en hitos teóricos de gran notabilidad para la reconstrucción del concepto de historia y de tiempo histórico. Esta reconceptualización de alguna manera pone en marcha un cambio de técnica expositiva.

La escritura de la historia, obviamente ante estos nuevos fenómenos conceptuales, tenía que cambiar, no podía seguir siendo lo que ha sido hasta el momento: una "narración de las cosas como efectivamente sucedieron y otras cosas semejantes" (Arostegui, 1995: 18) sino una práctica basada en la reflexión y el análisis histórico, una "vuelta al sujeto", un asunto más importante en su significación que aquel otro "retorno" que más se ha mencionado: la "vuelta del relato", interpretado muchas veces como sinónimo de la "narración" (descriptiva)" (Hernández, 1995: 49). "Se trata de dar paso con carácter alterativo a los nuevos conceptos: narración, frente a compresión, significado frente a explicación, historia literarioantropología frente a historia de fundamentación y predominio económico-social, tan duramente atacada en los últimos tiempos" (Hernández, 1995: 49).

Estas formas de pensar la historia desencadenan una renovación de las técnicas expositivas del relato. Pero no ya desde esa legitimación positivista que convertía a los grandes hombres en sujetos transcendentes reales inscritos en un plan superior y objetivo de la historia. Aquí la técnica narrativa responde a la simple necesidad, en la que insiste Hayden White, de percibir la realidad en su conformación coherente con principio y fin. La narración, como aparato semiótico que dota a los hechos desde su similitud y contigüidad, de un orden común instalado en el tiempo, donde supuestamente lo real se presenta como deseable y concebible en su terminación.

El relato, en definitiva, es un instrumento descriptivo imprescindible en la exposición de la historia, pero no es la historia. Los discursos argumentativos son el género más amplio de todos los discursos demostrativos y contiene en sí mismos el discurso científico. La forma indicada para un discurso historiográfico, verdaderamente representativo de la historia es la argumentación.

Sintetizando, el discurso historiográfico es un discurso analítico de un proceso bien delimitado, cuyo contenido son descripciones de situaciones en un proceso temporal y da resultados de las acciones de dicho proceso. Una historia no es una narración, es una argumentación y, en este sentido, es una teoría. De lo contrario sería literatura, no sería ciencia social (Hernández, 1995: 322).

En contraposición con Arostegui la narración es una forma de hablar tan universal como el propio lenguaje, y el modo de representación narrativo aparece muy natural a la conciencia humana; por ello su aspiración a la ciencia resulta sospechosa. Sin embargo, en el ámbito de los estudios históricos, la narrativa no ha solido ser considerada ni como un producto de una teoría ni como la base de un método sino más bien, como una forma de discurso que puede o no utilizarse para la representación de los acontecimientos históricos, en función de si el objetivo primario es describir una situación, analizar un proceso histórico o bien contar una historia (White, 1992: 42).

En este sentido, la narración, interpretada como una escritura no meramente registrada sino como lectura del mundo o de un suceso, cobra valor como instrumento de representación de dicho mundo o proceso histórico que se quiere contar. Para Roland Barthes, la narrativa es un fenómeno internacional transhistórico, transcultural: está simplemente ahí como la vida misma; en tanto que para Nietzsche la historia y su relato es siempre válido si sirve a la vida.

Mientras que Braudel, Furet, Le Goff, del grupo francés, consideraban la historiografía narrativa como no científica, los filósofos de orientación semiológica como Foucault, Derrida, Todorov, Kristeva, Benveniste, Genette, Eco, que han estudiado la narrativa en todas sus manifestaciones, la consideran un "código" discursivo entre otros que puede o no ser apropiado para la representación de la realidad. Es cuestión de la postura que tome el historiador como narrador o como científico, de donde la visión del mundo, del acontecimiento, o del proceso histórico es fuente refrescante o de difícil acceso para representar la realidad. Asimismo, es desde las posturas semiológicas como un lenguaje dotado de símbolos que representa ideas, conceptos, juicios, argumentos etc., para representar a su vez la misma realidad dentro de un contexto que para ser comprendido gira sobre sus goznes $y$ hace conexiones con otros contextos para construir un sistema intercontextual.

Ahora bien, según Ricour la historia es un conocimiento por huella, un efecto de signos, simbolos y textos que narra, señala y aclara la experiencia humana."Todo lo que se cuenta sucede en el tiempo, arraiga en el mismo, se desarrolla temporalmente; y lo que se desarrolla en el tiempo puede narrarse. "La función de la narratividad proporciona un tránsito 
desde la intratemporalidad a la historicidad y lo hace revelando lo que debe denominarse la naturaleza "de tipo trama" de la propia temporalidad (...) la temporalidad es aquella estructura de la existencia que alcanza el lenguaje en la narratividad y la narratividad la estructura del lenguaje que tiene a la temporalidad como referente último (...) la significación de está metafísica de la narratividad para la teoría historiográfica radica en la idea de Ricoeur de que la narrativa debe tener en virtud de su narratividad como su "referente último" no otra cosa que la propia "temporalidad" (Ricoeur, 1996: 748-749)

White es partidario tanto como los filósofos de orientación semiológica de la idoneidad del discurso narrativo para representar esa parte de la realidad que denominamos historia. De este modo, el único significado que puede tener la historia es la especie de significación que pueda otorgarse a una imaginación narrativa. Para él, el secreto del proceso por el cual la conciencia dota de significado a la historia esta en el "contenido de la forma", en la forma en que nuestras facultades narrativas transforman el presente en el cumplimiento de un pasado del que deseamos haber descendido. Este deseo surge como correspondencia de la narración contada como relato vivido por personas reales del pasado.

Esto resulta comprensible en el paralelo paradigmático de un historiador de Julio César describiendo los hechos de Julio César, quizás sus rasgos de carácter, de un modo relativamente objetivo sumando a ello sus logros, su capacidad intelectual de estadista y estratega militar. En tanto que un poeta por decir Shakespeare reescribe los relatos de Julio César para desnudar con un relato vívido, con una narración vibrante el alma de Julio César, sus pasiones y motivaciones. La persona de Julio César puede ser contemplada en su totalidad al unificar al historiador y al poeta. En otros términos, lo relativamente objetivo unido a lo profundamente subjetivo, donde cualquier ser humano podría ser cualquier ser humano.

Asimismo, la narración de relatos ha llevado a muchos investigadores a comprobar la autenticidad o proximidad factual de dichos relatos con sus hallazgos de tipo arqueológico o de enfoque hermenéutico social. No obstante, la narrativa sólo se problematiza cuando deseamos dar a los acontecimientos reales la forma de un relato. Precisamente porque los acontecimientos reales no se presentan como relatos resulta tan difícil su narrativización. Pero esta dificultad no es un obstáculo infranqueable si se matizan los acontecimientos con sus telones de fondo y sus posibilidades anexas.

Para concluir, la historiografía tradicional desde su invención por Herodoto, ha defendido la convicción de que la propia historia consiste en un agregado de relatos vividos, individuales y colectivos y que la principal tarea del historiador consiste en develar estos relatos y reescribirlos en una narración cuya verdad consistiría en la correspondencia de la narración contada por personas reales del pasado. De esta forma es como surge la transmisión cultural, la escritura en todas sus posibles formas y lecturas, y por último el libro.

Las motivaciones que precipitan la aparición de la escritura descansan sobre necesidades contables. Los primeros signos del lenguaje escrito representaban cosas o cantidades, la escritura se convirtió en un instrumento esencial del poder político funcional para la publicación de leyes y la organización administrativa. A pesar de que en un inicio la escritura tenía un uso limitado marca un hito en el desarrollo de la civilización como generadora de progreso sin precedentes. El ser humano no siempre poseyó una escritura más siempre tuvo a su lado una lectura de su realidad, una narratividad que salvaguardó su unidad cultural y sus agregados idiosincráticos. Esta es una razón por la que "el tiempo poseería tres grados de organización: la intratemporalidad, la historicidad y la temporalidad profunda" (White, 1992: 69).

Desde esta perspectiva y a tenor de otra interpretación, la primera abarca las primeras lecturas del mundo hasta la fragmentación y especificación histórica. La segunda cubre la narratividad como escritura, testimonio y divulgación hasta su metodología científica, y la última se refiere a principios de enfoques hermenéuticos contemporáneos y una aspiración totalizadora de la historia, y por ende, integradora. Fredric Jameson "llega hasta concebir la narrativa como un modelo de conciencia que hace posible un tipo de acción de naturaleza específicamente histórica"1. El tiempo da testimonio de la historia en la escritura.

\section{Referencias bibliográficas}

Arostegui, J. (1995). La investigación histórica: teoría y método. Barcelona: Crítica.

Braudel, F. (1986). Historiay las ciencias sociales. Madrid: Alianza.

Hernández, E. (1995). Los caminos de la historia. Cuestiones de historiografía y Método. Madrid: Síntesis.

Jaspers, K. (1981) Nietzche. Buenos Aires: Sudamericana.

Kula, W. (1974). Teoría económica del sistema feudal. México: Siglo XXI.

Le Goff, J. (1997). Pensar la historia. Barcelona: Paidós.

Levi-Strauss, C. (1970). Antropología estructural. Buenos Aires: Eudeba.

Lledó, E. (1978) Lenguaje e historia. Barcelona: Alas.

Riccur, P. (1996). El tiempo y narración III. México: Siglo XXI.

Ricour, P. (2000) Histoire et mémoire: l'écriture de l'histoire et la représentation du passé" Annales. Histoire, Sciences Sociales. No. $55-4$.

Veyne, P. (1995) Historia. Barcelona: Paidós.

White, H. (1992) El contenido de la forma. Barcelona: Paidós.

White, H. (2003). "Teoría literaria y escrito histórico". En El texto histórico como artefacto literario (Introducción de Verónica Tozzi, traducción Verónica Tozzi y Nicolás Lavagnino) Barcelona: Paidós.

1 - Fredric Jameson. Citado por White (1992: 161). 